\title{
Kontrol Diri dan Kecanduan Gadget pada Siswa Remaja
}

\author{
Layli Mumbaasithoh', Fiya Ma'arifa Ulya', Kukuh Basuki Rahmat' \\ 1Fakultas Psikologi, Universitas Gadjah Mada, Yogyakarta
}

DOI: http://doi.org/10.29080/jpp.v12i1.507

\begin{abstract}
Using gadgets uncontrolled can lead to addiction. This research aims to study the correlation between self-control and gadget addiction among teenagers in Yogyakarta who have online learning during the pandemic. The subjects were 30 teenagers. This correlational quantitative research uses the Pearson productmoment in data analysis. The results showed that self-control was negatively correlated with gadget addiction. The higher the self-control they have, the lower the tendency for teenagers will have gadget addiction. Besides, the data obtained through open-ended questions show several strategies carried out by students to have high self-control. They have time management, prefer doing other activities to having gadgets, and getting supervision from parents while having online learning.
\end{abstract}

Keywords : self control, gadget addiction, learning from home

\begin{abstract}
Abstrak : Penggunaan gadget yang tidak terkontrol pada siswa saat belajar dari rumah dapat menyebabkan kecanduan. Penelitian ini bertujuan untuk mengetahui hubungan antara kontrol diri dan kecanduan gadget pada siswa remaja di Daerah Istimewa Yogyakarta yang belajar dari rumah selama pandemi. Subjek penelitian berjumlah 30 siswa remaja. Penelitian kuantitatif korelasional ini menggunakan pearson product moment dalam analisis data. Hasil penelitian menunjukkan kontrol diri berkorelasi secara negatif terhadap kecanduan gadget. Semakin tinggi kontrol diri yang dimiliki maka semakin rendah kecenderungan remaja untuk mengalami kecanduan gadget. Selain itu data yang didapatkan melalui open ended questions menunjukkan sejumlah strategi yang dilakukan siswa agar memiliki kontrol diri yang tinggi yaitu melakukan manajemen waktu, mengerjakan kegiatan selain menggunakan gadget, dan mendapatkan pengawasan dari orang tua selama belajar dari rumah.
\end{abstract}

Kata kunci : kontrol diri, kecanduan gadget, belajar dari rumah

\section{Pendahuluan}

Kecanduan gadget merupakan fenomena yang berkaitan dengan penggunaan smartphone yang tidak terkendali (Soo Cha \& Kyung Seo, 2018). Remaja yang kecanduan smartphone cenderung melupakan tugas belajarnya dan juga pemenuhan kebutuhan dasar seperti makan, minum, atau mandi. Di sisi lain, individu dengan kecanduan gadget akan 
menghadapi masalah sosial, psikologis, dan kesehatan. Banyaknya waktu yang tersita untuk bermain gadget membuat individu jauh dari lingkungan sosialnya (Wardhani, 2018). Penggunaan gadget yang berlebihan juga dapat menurunkan daya aktif anak dan kemampuannya berinteraksi dengan orang lain (Chusna, 2017). Hal ini dikarenakan pengguna seolah-olah terserap dalam ekosistem yang dibentuk di dalam gadget.

Kecanduan gadget memiliki beberapa istilah lain yaitu kecanduan smartphone, kecanduan ponsel, penggunaan ponsel bermasalah/Problematic Mobile Phone Use (PMPU), penggunaan ponsel yang kompulsif, dan penggunaan ponsel berlebihan (Al-Barashdi dkk, 2015). Perilaku penggunaan media yang maladaptif dalam waktu yang berlebihan menyebabkan ketidaknyamanan dan terganggunya aktivitas sehari-hari (Kwan \& Leung, 2015; Kwon dkk, 2013; Lee \& Cho, 2015). Seorang remaja yang sudah kecanduan gadget dapat menghabiskan sebagian besar waktunya bersama gadget, bahkan tidak dapat terlepas dari gadget.

Penelitian Soo Cha dan Kyung Seo (2018) menemukan kecenderungan penggunaan gadget berlebihan pada siswa remaja. Penelitian yang dilakukan terhadap 1.824 siswa SMA di Korea Selatan menunjukkan sebanyak 30,9\% dikategorikan sebagai kelompok berisiko mengalami kecanduan smartphone. Mayoritas siswa menggunakan layanan mobile messenger, surfing internet, bermain game, dan mengakses jejaring sosial. Alasdair dan Philips (2017) juga menyebutkan bahwa kecanduan gadget dapat menyebabkan depresi, cemas, stres yang berkepanjangan hingga berdampak pada kesehatan fisik. Gangguan sistem saraf, gangguan tidur, masalah dengan gendang telinga, nyeri di beberapa bagian tubuh, dan kelelahan merupakan gejala yang banyak ditemukan.

Sebagian besar proses perilaku kecanduan disebabkan oleh kurangnya kontrol atas perilaku adiktif dan terhabituasi (Shirinkam dkk, 2016). Pengendalian diri yang rendah dapat dikatakan sebagai faktor resiko yang signifikan untuk berbagai masalah pribadi dan interpersonal (Tangney dkk, 2004). Kontrol diri diri merupakan mekanisme yang disengaja dan disertai dengan niat sehingga dapat mengubah perilaku, menahan godaan, mengubah suasana hati, dan bertindak untuk mencapai tujuan pribadi (Akın dkk, 2015). Sementara itu, menurut Baumeister dkk (2007) kontrol diri adalah kemampuan untuk mengendalikan respon atau menyesuaikan diri sehingga menghasilkan kesesuaian yang optimal dalam berperilaku yang sesuai demi tercapainya tujuan jangka panjang.

Penelitian Ningtyas (2012) melihat kontrol diri yang rendah pada mahasiswa dimana mahasiswa yang mengalami kecanduan internet yang ditandai dengan perhatian yang selalu tertuju pada internet, dan kurang mengontrol penggunaan internet. Akin, Arslan, Arslan, dkk (2015) juga menemukan bahwa mahasiswa yang mengalami kecanduan internet cenderung memiliki manajemen kontrol diri yang rendah. Penelitian yang dilakukan oleh Debora \& Sukmawati (2021), menemukan bahwa terdapat hubungan negatif antara kontrol diri terhadap penggunaan smartphone. Semakin tinggi kontrol diri yang dimiliki semakin rendah penggunaan smartphone pada siswa. Hasil penelitian Adiyatma dkk (2020) juga menemukan bahwa kontrol diri berkontribusi secara signifikan dan berkorelasi negatif dengan kecanduan smartphone. Semakin tinggi kontrol diri, semakin rendah tingkat kecanduan smartphone, sebaliknya semakin rendah kontrol diri semakin tinggi tingkat kecanduan smartphone.

Penelitian ini bertujuan untuk mengetahui seberapa besar kontrol diri dikaitkan dengan perilaku kecanduan gadget pada siswa yang melakukan belajar dari rumah. Menurut Soo Cha \& Kyung Seo (2018), remaja adalah kelompok yang memiliki resiko tinggi untuk kecanduan gadget. Remaja sangat terikat dengan gadget mereka, bahkan menganggapnya sebagai diri kedua. Penelitian ini ingin melihat hubungan antara kontrol diri dengan kecanduan gadget pada siswa remaja yang melakukan belajar dari rumah serta strategi siswa remaja dalam melakukan kontrol dirinya. 


\section{Metode Penelitian}

Penelitian ini menggunakan metode kuantitatif korelasional ditambah dukungan data kualitatif. Subjek penelitian dipilih dengan menggunakan metode convenience sampling. Partisipan dalam penelitian ini adalah 30 siswa remaja tingkat pendidikan SMP dan SMA di DIY yang melakukan belajar dari rumah. Pengumpulan data dilakukan secara online melalui google form. Data dianalisis secara statistik melalui uji korelasi Pearson Product Moment serta analisis terkait jawaban dari open ended questions.

Variabel kontrol diri diukur menggunakan skala kontrol diri versi Indonesia yang terdiri atas 10 aitem. Skala ini pada mengacu pada The Brief Self Control Scale (BSCS, Tangney, Baumeister, \& Boone, 2004) yang telah dioperasionalisasikan oleh De Ridder, dkk (2012). Variabel kecanduan gadget diukur menggunakan Smartphone Addiction Scale (SAS) (Kwon dkk,2013) yang terdiri dari 33 item. Peneliti juga menanyakan 3 butir open ended questions untuk menggali strategi siswa yang melakukan belajar dari rumah.

\section{Hasil Penelitian}

Hasil uji normalitas menunjukkan nilai signifikansi p sebesar 0,81 dan 0,71 , nilai $\mathrm{p}>0,05$ yang berarti data penelitian ini berdistribusi normal. Selain itu juga dilakukan uji lineritas denga nilai signifikansi sebesar $0,005, p<0,05$ yang berarti data tersebut mengikuti garis linier. Selanjutnya hasil uji korelasi Pearson Product Moment menunjukkan nilai signifikansi sebesar 0,003 atau $\mathrm{p}<0,05$. Nilai tersebut dapat dikatakan terdapat hubungan negatif antara self control dengan kecanduan gadget. Dengan kata lain semakin tinggi kontrol diri, maka kecenderungan yang mengarah pada perilaku kecanduan gadget semakin rendah.

Tabel 1

Hasil Uji Korelasi

\begin{tabular}{|ll|r|r|}
\hline & Self control & \multicolumn{2}{c|}{$\begin{array}{c}\text { Kecanduan } \\
\text { Gadget }\end{array}$} \\
\hline Self control & Pearson Correlation & 1 &, $489^{* *}$ \\
& Sig. (1-tailed) & &, 003 \\
& $\mathrm{~N}$ & 30 & 30 \\
\hline kecanduan Gadget & Pearson Correlation &, $489^{* *}$ & 1 \\
& Sig. (1-tailed) &, 003 & 30 \\
& $\mathrm{~N}$ & 30 & \\
\end{tabular}

Nilai korelasi (R) yang diperoleh adalah 0, 489, dengan nilai R Square 0, 239, sedangkan koefisien regresi yang telah disesuaikan (Adjusted $R$ Square) adalah 0,211 . Hal ini membuktikan bahwa kontrol memiliki kontribusi yang signifikan terhadap kecanduan gadget dengan kontribusi efektif sebesar $24 \%$, sedangkan sisanya sebesar $76 \%$ dipengaruhi oleh faktor lain.

Tabel 2

Pengaruh Variabel Prediktor

\begin{tabular}{ccccc}
\hline Model & $\mathrm{R}$ & R Square & Adjusted R Square & Std. Error of the Estimate \\
\hline 1 & $.489 \mathrm{a}$ & .239 & .211 & 17.939 \\
\hline
\end{tabular}


Peneliti juga melakukan pengambilan data dengan open ended questions untuk mencari tahu terkait bagaimana strategi yang dilakukan oleh para siswa agar memiliki kontrol diri yang tinggi ketika menggunakan gadget. Terdapat 3 pertanyaan open ended yang diajukan yaitu tentang bagaimana cara siswa membagi waktu antara belajar, bermain, dan istirahat, bagaimana cara membatasi waktu bermain gadget, serta bagaimana cara orangtua mengawasi siswa saat belajar online. Hasil analisis open ended questions sebagaimana tercantum dalam tabel berikut:

Tabel 3

Strategi Kontrol Diri Siswa Remaja

\begin{tabular}{|c|c|c|c|c|}
\hline \multicolumn{2}{|c|}{ Kategori } & \multirow{2}{*}{$\begin{array}{c}\mathbf{n} \\
18\end{array}$} & \multirow{2}{*}{$\begin{array}{c}\% \\
60 \%\end{array}$} & Sample Comments \\
\hline $\begin{array}{l}\text { Manajemen } \\
\text { Waktu }\end{array}$ & Dijadwalkan & & & $\begin{array}{l}\text { Belajar saat jam pelajaran, bermain setelah } \\
\text { tidak ada kelas, istirahat malam saat sudah jam } \\
21.00 \text {. } \\
\text { Saya membuat jadwal untuk belajar, bermain } \\
\text { dan istirahat kemudian disiplin dalam } \\
\text { melaksanakan. }\end{array}$ \\
\hline & Tidak dijadwalkan & 9 & $30 \%$ & $\begin{array}{l}\text { Tergantung sayanya kalau lagi mau belajar ya } \\
\text { belajar. Kalau mau main ya main, istirahat ya } \\
\text { istirahat. Tergantung jadwal sekolah sama PR } \\
\text { dari sekolah. } \\
\text { Waktu untuk membagi semuanya itu nggak } \\
\text { nentu kalau saya, setiap hari bisa berubah-ubah, } \\
\text { yang biasanya jam segini istirahat, ternyata } \\
\text { harus belajar. Jadi nggak menentu kalau saya } \\
\text { tergantung situasi sama sayanya sendiri. }\end{array}$ \\
\hline & Tidak tahu & 3 & $10 \%$ & $\begin{array}{l}\text { Belum tau tau caranya. } \\
\text { Masih sering bingung. } \\
\text { Tidak tahu. }\end{array}$ \\
\hline \multirow[t]{7}{*}{ Kontrol Diri } & Healthy habits & 10 & $33 \%$ & $\begin{array}{l}\text { Bermain voli. } \\
\text { Dengan membantu orang tua. } \\
\text { Bermain dengan orang lain, teman atau } \\
\text { keluarga. }\end{array}$ \\
\hline & Self dicipline & 3 & $10 \%$ & $\begin{array}{l}\text { Mematikan data hp dan mode daya mati. } \\
\text { Memasang alarm. }\end{array}$ \\
\hline & Work ethics & 6 & $20 \%$ & $\begin{array}{l}\text { Saya membuat perjanjian dengan diri dan hati } \\
\text { saya agar bisa membatasi penggunaan gadget. } \\
\text { Kalau semisal saya belum bisa komit maka saya } \\
\text { akan terus berusaha untuk mengatasinya dan } \\
\text { sambil mengingatkan ke diri saya bahwa HP itu } \\
\text { hanyalah kesenangan sementara dan akan } \\
\text { berakibat buruk bagi masa depan jika } \\
\text { menyalahgunakan dan terlalu berlebihan. }\end{array}$ \\
\hline & Reliability & 1 & $\begin{array}{c}3,33 \\
\%\end{array}$ & $\begin{array}{l}\text { Saya tidak bermain, mungkin hanya saya } \\
\text { gunakan untuk bersekolah online yang mungkin } \\
\text { tidak disukai banyak orang. }\end{array}$ \\
\hline & $\begin{array}{l}\text { Deliberation/Non } \\
\text { impulsive }\end{array}$ & 6 & $20 \%$ & $\begin{array}{l}\text { Tidak terlalu lama menggunakannya. } \\
\text { Menggunakan gadget hanya saat merasa bosan } \\
\text { atau karena ada kepentingan. }\end{array}$ \\
\hline & $\begin{array}{c}\text { Tidak } \\
\text { Menjawab/tidak } \\
\text { tahu/jawaban kurang } \\
\text { jelas }\end{array}$ & 3 & $10 \%$ & $\begin{array}{l}\text { Belum tau. } \\
\text { Dengan memberi waktu. }\end{array}$ \\
\hline & $\begin{array}{l}\text { Kontrol kurang baik/ } \\
\text { rendah }\end{array}$ & 1 & $\begin{array}{c}3,33 \\
\%\end{array}$ & $\begin{array}{l}\text { Saya masih belum bisa membatasi waktu } \\
\text { bermain gadget saya. }\end{array}$ \\
\hline Peran Orangtua & Mengawasi anak & 24 & $80 \%$ & $\begin{array}{l}\text { Orang tua saya sering duduk di sebelah saya } \\
\text { dan mengawasi saya belajar online. } \\
\text { Mereka masuk kamar untuk mengecek bahwa } \\
\text { saya memang belajar. }\end{array}$ \\
\hline
\end{tabular}




\begin{tabular}{|c|c|c|c|}
\hline $\begin{array}{c}\text { Tidak mengawasi } \\
\text { anak }\end{array}$ & 6 & $20 \%$ & $\begin{array}{l}\text { Jarang diawasi. } \\
\text { Tidak mengawasi. } \\
\text { Orang tua (ibu) saya sibuk menjaga adik dan } \\
\text { bekerja, ayah saya pun juga begitu. }\end{array}$ \\
\hline
\end{tabular}

\section{Pembahasan}

Hasil analisis data menunjukkan terdapat hubungan negatif antara kontrol diri dengan internet addiction. Hal itu menjelaskan bahwa remaja dengan kontrol diri tinggi cenderung tidak mengarah pada perilaku kecanduan gadget. Sebaliknya, remaja yang memiliki kontrol diri rendah cenderung mudah untuk kecanduan gadget. Hasil ini sesuai dengan penelitian Sulistyo dkk (2020), yang juga melihat kontrol diri yang tinggi terhadap internet mempengaruhi cara remaja untuk tidak tenggelam terhadap penggunaan internet dan mampu menggunakan internet sesuai dengan kebutuhan.

Kecanduan gadget terjadi ketika individu tidak dapat bersikap disiplin terhadap kehidupannya. Penelitian yang dilakukan Adlya dkk (2020) terhadap 275 siswa mengenai pengaruh self-control dengan disiplin pada siswa menunjukkan bahwa terdapat hubungan yang signifikan antara kontrol diri dengan disiplin pada siswa. Penelitian Putri \& Prasetyaningrum (2018) juga menemukan hubungan kontrol diri dengan intensitas bermain game online pada siswa sekolah dasar. Semakin tinggi kontrol diri pada siswa semakin rendah intensitas bermain game online pada siswa. Besarnya nilai sumbangan kontrol diri sebesar $64,6 \%$ menunjukkan intensitas bermain game online lebih dipengaruhi oleh kontrol diri, selebihnya dipengaruhi oleh variabel yang lainnya.

Bhattacharyya (2015) juga mengungkapkan bahwa ketergantungan pada teknologi menyebabkan hilangnya produktivitas secara signifikan dan dapat menimbulkan masalah dalam hubungan interpersonal. Kondisi ini disebabkan bahwa dalam proses sebagian besar perilaku adiktif dikarenakan kurangnya kontrol atas tindakan adiktif tersebut dan perilaku yang sudah terhabituasi (Shirinkam dkk, 2016). Jadi, apabila remaja memiliki kontrol diri yang rendah, salah satu perilaku negatif yang dapat ditimbulkan adalah penggunaan gadget yang berlebihan.

Dalam penelitian ini ditemukan bahwa mayoritas remaja mempunyai kontrol diri yang sedang (23 orang), sebanyak 7 orang dengan kontrol diri yang rendah, dan tidak ada yang memiliki kontrol diri tinggi. Dari kategorisasi tersebut dapat dijelaskan bahwa remaja dalam penelitian ini memiliki kontrol diri yang cukup baik. Kontrol diri yang baik akan berdampak pada berbagai domain dalam kehidupan (Baumeister, Vohs, \& Tice, 2007). Penggunaan yang tidak terkontrol, tidak dapat mengendalikan diri, dan berlebihan dalam penggunaan gadget merupakan ciri perilaku kecanduan gadget.

Selanjutnya, peneliti juga menggunakan open ended questions untuk mengetahui bagaimana strategi yang dilakukan oleh siswa agar memiliki kontrol diri yang tinggi. Open ended terdiri dari tiga pertanyaan yang meliputi pertanyaan manajemen waktu remaja, kontrol diri yang dilakukan, dan peran orangtua dalam mengawasi anak. Kondisi subjek penelitian sangat beragam. Begitu pula strategi pengendalian diri dan kondisi keluarga berbeda-beda diantara subjek. Hasil analisis open ended terkait manajemen waktu, sebanyak $60 \%$ siswa mengungkapkan bahwa mereka membuat jadwal sehari-hari agar dapat membagi waktu antara belajar, bermain, dan beristirahat.

Beberapa jawaban yang disampaikan oleh siswa terkait pengaturan waktu yang diterapkan adalah sebagai berikut:

"Saya membuat sebuah jadwal pada malam hari sebelum tidur atau tepatnya saat waktu belajar malam. Jadwal itu berisi tentang kegiatan penting besok, kemana aja besok, waktu buka hp, dll." 
"Belajar saat jam nya, bermain setelah tidak ada kelas, istirahat malam saat sudah jam 21.00."

"Menentukan waktu dimana saya harus wajib belajar, dimana saya bisa bermain dan istirahat. Lebih ke membuat jadwal jam jam saya harus melakukan aktivitas itu."

Jawaban tersebut menunjukkan bahwa subjek berusaha membuat jadwal yang konkrit sehingga membentuk sebuah pola yang mudah diikuti dan dijalankan. Hal ini bisa menjadi pedoman bagi remaja untuk menghindari penggunaan gadget pada waktu belajar atau menghentikan ketika merasa sudah melebihi waktu yang ditentukan.

Sejumlah 30\% siswa tidak membuat jadwal karena cenderung menerapkan fleksibilitas dalam menentukan kapan mereka harus belajar, bermain, dan beristirahat. Dengan kata lain, mereka cenderung mengatur aktivitas berdasarkan kondisi emosi atau sesuai keinginan sendiri.

"Tergantung sayanya kalau lagi mau belajar ya belajar. Kalau mau main ya main, istirahat ya istirahat. Tergantung jadwal sekolah sama PR dari sekolah."

"Waktu untuk membagi semuanya itu gak nentu kalo saya,setiap hari bisa berubah rubah, yang biasanya jam segini istirahat,ternyata harus belajar. Jadi gak nentu kalau saya tergantung situasi sama sayanya sendiri."

"Saya coba berusaha untuk memperhatikan sekiranya mana yang diprioritaskan.ya walaupun sempat beberapa kali saya melakukan kegiatan yang sebenarnya tidak begitu penting hanya buat senang-senang saja. Namun saya coba berusaha untuk mendahulukan mana yang sekiranya harus diprioritaskan."

Para siswa cenderung berusaha mengatur dirinya sendiri untuk dapat mengikuti pola baru yang terbentuk ketika dilaksanakannya belajar dari rumah di masa pandemi. Hal ini juga bermanfaat untuk membatasi remaja dari penggunaan gadget secara berlebihan.

Selanjutnya, sebanyak 10\% siswa mengaku bahwa mereka tidak tahu atau masih bingung bagaimana cara membagi waktu antara belajar, bermain, dan beristirahat. Jawaban yang disampaikan yaitu, "Belum tau tau caranya.", "Masih sering bingung.", "Tidak tahu." Dari jawaban tersebut dapat diketahui bahwa kondisi di masa pandemi ini tidaklah mudah. Ada remaja yang merasa kebingungan dan tidak tahu harus bagaimana untuk dapat menyesuaikan diri dengan pola kehidupan sehari-hari yang berubah secara drastis.

Pada pertanyaan open ended yang kedua, peneliti menanyakan terkait cara siswa membatasi waktu dalam penggunaan gadget. Peneliti bermaksud mencari tahu strategi pengendalian diri atau cara yang dilakukan siswa untuk membatasi diri terhadap penggunaan gadget. Hasilnya menunjukkan ada 3 aspek kontrol diri yang memiliki persentase cukup tinggi yaitu sebanyak 33\% siswa melakukan aktivitas healthy habits, $20 \%$ menerapkan work ethic, dan 20\% menunjukkan aspek deliberate/non impulsive. Healthy habits yang diterapkan oleh remaja yaitu dengan melakukan beberapa aktivitas fisik untuk menghindari diri dari paparan gadget terlalu lama. Beberapa jawaban yang diungkapkan oleh remaja seperti, "Bermain voli.", "Dengan membantu orang tua.", "Jalanjalan.", "Dengan bermain sepak bola di lapangan." dan sebagainya.

Sementara itu, ada remaja yang menerapkan etika kerja yang mereka coba buat dan sepakati sendiri sebagai sebuah peraturan harian yang mengikat. Salah satu subjek ada yang menjawab sebagai berikut:

"Saya membuat perjanjian dengan diri dan hati saya agar bisa membatasi penggunaan gadget, kalau semisal saya belum bisa komit maka saya akan terus berusaha untuk mengatasinya dan sambil mengingatkan ke diri saya bahwa HP itu 
hanyalah kesenangan sementara dan akan berakibat buruk bagi masa depan jika menyalahgunakan dan terlalu berlebihan".

Peneliti juga menjumpai jawaban remaja yang cenderung sengaja untuk tidak membebaskan dirinya atau berperilaku non impulsive dalam menggunakan gadget, seperti tergambar dari jawaban subjek.

"Menggunakan gadget hanya saat merasa bosan atau karena ada kepentingan."

"Membuka hp saat ada perlu saja seperti berkabaran dengan WA dan sebagainya."

Adapun siswa yang menjalani self discipline sebanyak 10\%, reliability sebesar $3,33 \%$. Selain itu siswa menjawab bahwasannya mereka belum tahu, pengendalian diri yang masih kurang, serta ada siswa yang tidak menjawab terkait pertanyaan membatasi waktu menggunakan gadget. Self discipline yang dilakukan oleh siswa adalah mematikan koneksi internet, mematikan gadget, dan menyalakan alarm untuk mengingatkan batas waktu menggunakan gadget. Dari 30 subjek penelitian, hanya ada satu siswa yang cenderung mempunyai kontrol yang kurang baik terhadap gadget. Kondisi ini tercermin dari jawaban subjek, "Saya masih belum bisa membatasi waktu bermain gadget saya."

Berdasarkan jawaban tersebut peneliti menganalisis bawa mengendalikan diri dari penggunaan gadget yang terlalu sering bukanlah hal yang mudah bagi semua orang, termasuk remaja. Apalagi remaja saat ini merupakan remaja hidup di era serba digital atau generasi digital natives. Prensky (2001) mengungkapkan apabila generasi yang lahir dengan adanya kemudahan teknologi yang muncul akan sulit terlepas dari benda-benda tersebut. Dukungan orangtua pada remaja mempengaruhi perkembangan masa remaja, dimana masa remaja masih membutuhkan belongingness. Remaja sebagai individu mempunyai perasaan ingin didukung, diterima, dihormati, dan dilibatkan oleh orang lain termasuk keluarga bahkan orang tua. Remaja yang salah mencari suatu kebutuhan belongingness cenderung memiliki strategi yang (Chen, 2003).

Peneliti mengkategorikan jawaban subjek menjadi dua yaitu orangtua yang cenderung mengawasi anak dan yang tidak mengawasi anak selama BDR. Hasilnya menunjukkan sebanyak $80 \%$ orangtua subjek mengawasi dan $20 \%$ orangtua subjek tidak mengawasi saat belajar dari rumah. Kondisi ini tercermin dari jawaban-jawaban yang dipaparkan oleh subjek.

"Orang tua saya sering duduk di sebelah saya dan mengawasi saya belajar online."

"Dengan selalu menanyakan tentang pembelajaran online nya."

"Ketat dan selalu menanyakan apa yg sedang saya lakukan untuk memastikan bahwa saya tidak menggunakan gadget terlalu lama untuk hal yg tidak penting seperti menonton youtube atau pun bermain game. Serta memberi motivasi-motivasi agar tidak terlalu mementingkan gadget."

"Mereka masuk kamar untuk mengecek bahwa saya memang belajar."

Di luar itu, terdapat orang tua yang kurang maupun tidak mengawasi anaknya karena kesibukan mereka bekerja. Ada dua responden yang menceritakan tentang kendala kesibukan yang menyebabkan orang tua tidak memiliki waktu untuk mengawasi anaknya.

"Kebetulan orang tua saya itu, ibu dokter kalau bapak dosen. Setiap hari mereka masuk kerja kecuali di hari sabtu dan ahad, orang tua saya libur. Jadi saya belum pernah melihat mereka mengawasi saya, paling hanya membantu pembelajaran saja, kalau mengawasi mereka tidak mengawasi saya belajar. Kebetulan sekolah saya ini hari sabtu dan ahad masuk jumatnya libur." 
"Orang tua (ibu) saya sibuk menjaga adik dan bekerja, ayah saya pun juga begitu." Sedangkan subjek penelitian yang lainnya hanya menjawab dengan jawaban pendek seperti "Jarang diawasi", "Tidak mengawasi", dan "Tidak diawasi."

Berdasarkan hasil penelitian yang telah dilakukan, secara umum kontrol diri pada siswa remaja yang melakukan belajar dari rumah cenderung baik. Kontrol diri tersebut juga memiliki korelasi negatif dengan perilaku kecanduan gadget sehingga siswa cenderung dapat mengendalikan diri dalam menggunakan gadget. Adapun strategi yang dilakukan meliputi manajemen waktu penggunaan gadget, melakukan kontrol diri, menerapkan kebiasaan sehat, disiplin diri, etika kerja, perilaku non impulsif, dan reliabitas. Selain itu, adanya peran dari orangtua dalam mengawasi anak selama belajar dari rumah juga menjadi faktor yang menyumbang kontrol diri siswa terhadap penggunaan gadget. Di sisi lain, temuan juga menunjukkan bahwa terdapat siswa yang memiliki kontrol diri cenderung rendah, tidak memiliki manajemen waktu, dan juga orangtua yang kurang mengawasi anak dalam BDR.

\section{Simpulan dan Saran}

Kontrol diri yang baik bagi remaja memang mempunyai hubungan negatif terhadap kecanduan gadget. Semakin tinggi nilai kontrol diri yang dimiliki remaja semakin rendah nilai perilaku kecanduan gadget pada remaja. Kontrol diri yang dilakukan oleh remaja pun bermacam-macam. Berdasarkan pertanyaan open ended, usaha yang dilakukan subjek untuk mengurangi penggunaan gadget adalah dengan manajemen waktu, mengontrol diri, dan mendapat dukungan dengan adanya pengawasan orang tua.

Penelitian ini memiliki beberapa keterbatasan. Variabel yang diteliti sudah banyak digunakan penelitian sebelumnya dan menunjukkan hasil yang sama bahwa kontrol diri memiliki hubungan negatif dengan kecanduan gadget. Penggunaan variable lain dapat menjadi alternatif untuk penelitian selanjutnya. Keterbatasan kedua terkait sampel yang berdasarkan keterjangkauan peneliti sehingga subjek penelitian tidak dapat merepresentasikan populasi secara umum. Mengingat situasi pandemi Covid-19 yang belum usai, peneliti tidak dapat melakukan observasi dan wawancara secara langsung sehingga hanya menggunakan open ended questions yang diisi secara online.

\section{Daftar Pustaka}

Adlya, S. I., Yusuf, A. M., \& Effendi, Z. M. (2020). The Contribution of Self Control to Student Discipline. Journal of Counseling and Educational Technology, 3(1), 1-5

Akın, A., Arslan, S., Arslan, N., Uysal. R., Sahranç, U. (2015). Self-control Management and Internet Addiction. International Online Journal of Educational Sciences, 2015, 7 (3), 95-100.

Al-Barashdi, H. S., Bouazza, A. \& Jabur, N. H. (2014). Smartphone Addiction Among University Undergraduates: A Literature Review. Journal of Scientific Research and Reports, 4(2), 210-225. DOI: https://doi.org/10.9734/ISRR/2015/12245

Arifin, H. H., \& Milla, M. N. (2020). Adaptasi dan Properti Psikometrik Skala Kontrol Diri Ringkas Versi Indonesia. Jurnal Psikologi Sosial 2020, 18(2), 179-195, Special Issue, DOI: $10.7454 /$ jps.2020.18

Asosiasi Penyelenggara Jasa Internet Indonesia (APJII). (2018). Potret Zaman Now Pengguna dan Perilaku Internet Indonesia. Buletin APJII. Edisi 23-April 2018

Asosiasi Penyelenggara Jasa Internet Indonesia (APJII). (2017). Infografis Penetrasi dan Perilaku Pengguna Internet Indonesia Survei 2017. Jakarta: APJII.

Baumeister, R. F., Vohs, K. D., \& Tice, D. M. (2007). The Strength Model of Self Control. Current Directions in Psychological Science, 16(1), 351-355. DOI: https://doi.org/10.1111/j.1467-8721.2007.00534.x 
Bhattacharyya, R. (2015). Addiction to Modern Gadget and Technologies Across Generations. Eastern Journal of Psychiatry, 18(2), 24-30

Chusna, P. A. (2017). Pengaruh Media Gadget pada Perkembangan Karakter Anak. 17(2), 23-30

Chasanah, A. M., \& Kilis, G. (2018). Adolescents' Gadget Addiction and Family Functioning. Advances in Social Science, Education and Humanities Research, volume 139 Published by Atlantis Press.

Dhamayanti, M., Dwiwina, R. G., \& Adawiyah, R. (2019). Influence of Adolescents' Smartphone Addiction on Mental and Emotional Development in West Java, Indonesia. Majalah Kedokteran Bandung, Volume 51 No. 1, March 2019

Dörnyei, Z. (2007). Research Methods In Applied Linguistics. New York: Oxford University Press.

Etikan, I., Musa, S. A., \& Alkassim, R. S. (2016). Comparison of Convenience Sampling and Purposive Sampling. American Journal of Theoretical and Applied Statistics. 5(1), 1-4. DOI: https://doi.org/10.11648/j.ajtas.20160501.11

Hurlock, E.B. (2008). Psikologi Perkembangan: Suatu Pendekatan Sepanjang Rentang Kehidupan. Jakarta : Erlangga.

Jahja, Y. (2012). Psikologi Perkembangan. Jakarta : Kencana.

Lee, J., \& Cho, B. (2015). Effects of Self-Control and School Adjustment on Smartphone Addiction among Elementary School Students. International Journal of Contents, 11(3), 15-20, DOI: http://doi.org/10.5392/IJoC.2015.11.3.001

Kemdikbud.go.id. (2020). Penyesuaian Keputusan Bersama Empat Menteri tentang Panduan Pembelajaran di Masa Pandemi Covid-19. Jakarta: Kemdikbud.

Kwan, H. C. \& Leung, M. T. (2015). The Path Model of Parenting Style, Attachment Style, Self-Regulation and Smartphone Addiction. In Jane M. Montague \& Lee Ming Tan (Ed.), Applied Psychology Proceedings of the 2015 Asian Congress of Applied Psychology (ACAP 2015) (pp. 108-131). Singapore: World Scientific Publishing Company.

Kwon, Min., Kim, Dai-Jin., Cho, Hyun., \& Yang, Soo. (2013). The Smartphone Addiction Scale: Development and Validation of a Short Version for Adolescents. PLOS ONE, 8(12), 40-45.

Milla, M. N., \& Arifin, H. H. (2020). Adaptasi dan Properti Psikometrik Skala Kontrol Diri Ringkas Versi Indonesia. Jurnal Psikologi Sosial, 18(2), 179-195, DOI: https://doi.org/10.7454/ips.2020.18

Muflih, M., Hamzah, H., \& Puniawan, A. (2017). Penggunaan Smartphone dan Interaksi Sosial pada Remaja di SMA Negeri 1 Kalasan Sleman Yogyakarta. Idea Nursing Journal, Vol. VIII No.1, 2017 ISSN : 2087-2879, e-ISSN : 2580 - 2445

Ningtyas, S. D. Y. (2012). Hubungan Antara Self Control Dengan Internet Addiction Pada Mahasiswa. Educational Psychology Journal, 1 (1), 15-26.

Obinna, E. N., \& Kabari, L. G. (2018). Generations of Internet (Past, Present, and Future). International Journal of Computer Applications, 181(9), 889-899.

Pamungkas, C. (2015). Global Village dan globalisasi dalam konteks ke-Indonesiaan. Global \& Strategis, 9(2), 20-28.

Prensky, M. (2001). Digital Natives, Digital Immigrant : On The Horizon. MCB University Press. Vol 9(5), 15-19

Putri, N. F.R., \& Prasetyaningrum, S. (2018). The Relationship Between Self Control with Intensity of Playing Online Games on the School Children. Jurnal PSIKODIMENSIA, $17(2), 51-56$.

Santrock, J. W. (2012). Life-Span Development; Perkembangan Masa Hidup Edisi Ketigabelas Jilid I. Jakarta: Penerbit Erlangga. 
Shirinkam, M. S., Shahsavarani, A. M et. al (2016). Internet Addiction Antecedents: SelfControl As a Predictor. International Journal of Medical Research \& Health Sciences, 5(5), 143-151

Soo Cha, S., \& Kyung Seo, B. (2018). Smartphone Use And Smartphone Addiction In Middle School Students In Korea: Prevalence, Social Networking Service, And Game Use. Health Psychology Open, 6(2), 1-15. DOI: https://doi.org/10.1177/2055102918755046

Soltysik-Piorunkiewicz, A. (2013). The Development of Mobile Internet Technology and Ubiquitous Communication in a Knowledge-Based Organization. Online Journal of Applied Knowledge Management,1(1), 27-34

Sulistio, E. N., Puspa, D. R., Dwi, D. I., Anggoro, H., Ervin, M. S., \& Kiereda, S. K. (2020). Hubungan Self Control dengan Internet Addiction pada Remaja. Jurnal Psikologi Wijaya Putra, 1(3), 61-68

Suseno, M. N. (2012). Statistika Teori dan Aplikasi untuk Penelitian Ilmu Sosial dan Humaniora. Yogyakarta: Penerbit As Shaff.

Tangney, J. P., Baumeister, R. F., \& Boone, A. L. (2004). High Self-Control Predicts Good Adjustment, Less Pathology, Better Grades, and Interpersonal Success. Journal of Personality, 72(2), 45-53

Wardhani, F. P. (2018). Student Gadget Addiction Behavior in the Perspective of Respectful Framework. Konselor, 7(3), 35-42, DOI: https://doi.org/10.24036/0201872100184$\underline{0-00}$

Waycott, J., Bennett, S., Kennedy, G., Dalgarno, B., \& Gray, K. (2010). Digital Divides? Student And Staff Perceptions Of Information And Communication Technologies. Computers \& Education, 54 (2), 1202-1211, DOI: https://doi.org/10.1016/j.compedu.2009.11.006 